\section{EDITORIAL}

\section{A RAE E AS REDES ORGANIZACIONAIS}

Em constante evolução, a Escola de Administraçăo de Empresas de São Paulo da Fundaçäo Getulio Vargas aprimora os conceitos e a utilização das redes organizacionais. Como parte integrante desta nova forma de atuação, a RAE deverá desempenhar um papel estratégico no desenvolvimento e na sustentaçăo dessas redes. A partir desta edição, mudà-se o enfoque a RAE, que era una unidade de negócios, passará a ser tratada como o órgão de divulgação da EAESP/FGV. Na esteira desta inovaçäo, além de ser um canal privilegiado para a veiculaçăo do pensamento eaespiano sobre gestão, a RAE atuará também como elemento de fidelizaçăa da clientela da Escola. Assim, os participantes do GVpec - Programa de Educaçäo Continuada para Executivos - receberão gratuitamente uma assinatura da RAE por um ano e a seçäo Tecnologias de Gestão será cativa do GVpec. Estuda-se a ampliaçãa deste quadro de assinantes para alunos de graduaçăo, mestrado, doutorado e especializaçăo. Da mesma forma, os professores da EAESP receberäo exemplares da revista, se assim o desejarem. Neste último número de 1997, contempla-se o tema Redes Organizacionais que é abordado sob diferentes perspectivas em vários artigos. Em "Terceirizaçăo: a integraçăo acabou", o professor Wilson Fezende examina os desdobramentos da terceirização. No artigo da professora Maria Cecilia Coutinho de Arruda e Marcelo Leme, as redes organiza. cionals são anailsadas sob o entoque das alianças estratégicas em marketing. Outras dimensöes das redes sä̃o apresentadas em artigos de Andres Marinakis (sobre a participaçăo dos trabalhadores nos lucros e resultados das empresas) e Jaci Corrêa Leite (sobre terceirizaçăo em informática). Ainda que não especiticamente sobre redes, este número inclui os artigos de José Carlos Durand et alii (sobre patrocínio à cultura), de Emmanuel Roussakis (sobre a origem e evoluçăo do global banking) e de José Roberto Ferro (sobre os Circulos de Controle de Qualida. de no Brasil). 0 conjunto de artigos se completa com o artigo de Leticia Pena e Dayr Reis sobre Student Stress and Quality of Education. A R,AE Light, por sua vez, oferece-nos è leitura um artigo bastante original sobre Marketing da Moda e uma releitura da competiçầo entre empresas sob o ponto de vista da formaçäo de equipes. Este número inclui ainda duas resenhas. $O$ assunto Redes Organizacionals deverá ser objeto de atenção no ensino de administração por um bom tempo pois está intimamente relacionado com tudo o que é percebido como o que existe de mais moderno em gestäo e a RAE pretende acompanhar a evoluçẫo destas tendências.

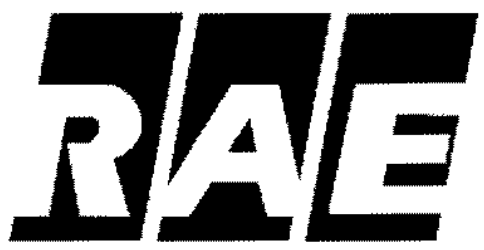

VOLUME 37

NÜMERO 4

OUT.JDEZ. 1997

\section{Organização, Recursos Humanos e Planejamento}

\section{Terceirização: a integração acabou?}

Wilson Rezende

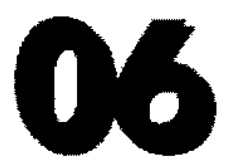

sediadas no Brasil que, nos últimos anos, fizeram uso dessas estratọglias.

This article intends to provide a conceptual analysis of the main tactors linked to integration and activity shiaring and also provides a survey of those entreprises setted in Brazil and which, lately, have been using those strategies.

\title{
Student stress and quality of education
}

Letf́cia Pena e Dayr Reis

O antigo analisa o stress do estudarte utilizanto o modelo de Mclean sobre contexto, winerabilidade e fatores da stress, para avaliar como um grupo de estudantes de administraçẫo enfrentà o stress cotidiano e sugere medidas pata reduzir os seus efétos prejudiciais e melhorar a qualidade do ensino.

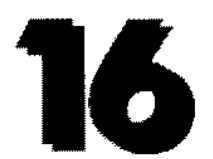

The paper focuses on student stress, using a framework based on Mclean's model of context, wherabitity and stressors to assess how a group of butsiness students is coping with stress. The article suggests several measures to make the context of leanning and teaching more supportive and collaborative.

\section{Administração Mercadológica}

\section{Alianças estratégicas internacionais: formação e estruturação em indústrias manufatureiras}

Maria Cecilia Coutinho de Arruda e Marcelo Leme de Arruda

A estralegia de negócios intemacionais de indústrias latino-

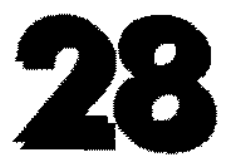
americanas e a forma como se conduzem slas parcerias com indistrias estrangeiras sto analisadas como objetivo de corthecer methor aspectos como: 1. implementaçäo de uma estratégia intemacional bem-sucedida; 2. torna como as empresas conduzem suas relaçóces com empresas de outros países; 3 . deteminaçäo dos fatores de sucesso dessas alianças de nejocios intemacionais.

Latin American manutacuing fims' intemational strategy and management of their aliances with foregon companies ara aralysed whit focus on: 1 . molementing a successuil intemational strategr; 2 understanding how Latin Amencan fims manage their relationshous with companies from foreign countries; 3 . determining the success faciors of these cross-national business allances. 